\title{
Thermal Response Simulation of Ultra Light Weight Phenolic Carbon Ablator by the Use of the Ablation Analysis Code
}

\author{
Sumio KATO $^{1)}$, Keiichi OKUYAMA ${ }^{2}$, Kenta GIBO $^{1}$, Takuma MiYAGI $^{1}$, , Toshiyuki SUZUKI ${ }^{3)}$, \\ Kazuhisa FUJITA $^{3)}$, Takeharu SAKAI ${ }^{4)}$, Seiji NISHIO ${ }^{5)}$ and Akihiro WATANABE ${ }^{1)}$ \\ ${ }^{1)}$ University of the Ryukyus, 1 Senbaru, Nishihara, Okinawa, Japan \\ ${ }^{2)}$ Aichi University of Technology, 50-2, Manori, Nishihazama, Gamagori, Aichi, Japan \\ ${ }^{3)}$ Japan Aerospace Exploration Agency, 7-44-1 Jindaiji-Higashi-machi, Chofu, Tokyo Japan \\ ${ }^{4)}$ Nagoya University, Furo-cho, Chikusa-ku, Nagoya, Aichi, Japan \\ ${ }^{5)}$ Kawasaki Heavy Industries, Ltd., 1 Kawasaki, Kakamigahara, Gifu, Japan
}

(Received June 28th, 2011)

\begin{abstract}
A space vehicle which undergoes the atmospheric re-entry or a planetary entry needs the heat shield system to protect inner equipments against severe aerodynamic heating environments. Charring ablator is usually used for the heat shield system. In order to design the heat shield system, it is necessary to predict the thermal behavior under aerodynamic heating by ablation analysis. A computer code for charring ablation and thermal response analysis is newly developed for simulation of one-dimensional transient thermal behavior of charring ablation materials. The mathematical model for the charring ablation including basic equation and computational method of ablation analysis is briefly described. A new ultra light weight phenolic carbon ablator called LATS (Lightweight Ablator series for Transfer vehicle) was recently developed. Arc-heated tests of the LATS ablator were carried out and measured results of the temperature response and surface mass loss are compared with the simulation results of the ablation analysis program. The agreement between the results of simulation and measurement is found to be good. It is also found that the mathematical model used in the ablation code can be applied to the ablation analysis of the low density LATS ablator.
\end{abstract}

Key Words: Ablator, Heat Shield System, Re-entry Capsule

\section{Introduction}

A space vehicle which undergoes the earth atmospheric re-entry or a planetary entry needs the heat shield system to protect inner equipments against severe heating environments during the earth re-entry or a planetary entry, and the surface temperature of the vehicle becomes very high by aerodynamic heating. Usually the heat shield system is mainly made of ablative material which is able to prevent the heat transfer to the inside by an ablation phenomenon. Charring ablator is usually used for the heat shield system. Among charring ablators, phenolic carbon ablator is often used for the heat shield system. The phenolic carbon ablator has been applied to the earth re-entry capsules such as USERS REV capsule ${ }^{1)}$ (Unmanned Space Experiment Recovery System REcovery Vehicle) and Hayabusa Re-entry capsule ${ }^{2)}$ or the planetary entry probe "Gallileo" of NASA. ${ }^{3)}$ Each of these capsules used a high density ablator with the value of about $1500 \mathrm{~kg} / \mathrm{m}^{3}$. On the other hand, the use of a low density ablator gives a weight reduction of the heat shield system, and the lightweight ablator with the density values of about $300 \mathrm{~kg} / \mathrm{m}^{3}$ has been developed $^{4)}$ and used for the heat protection of the Stardust Capsule $^{5)}$. Recently, a lightweight ablator named LATS (Lightweight ablator series for Transfer Vehicle) has been developed $^{6)}$, the density of which is lower by about one-fifth of the carbon phenolic ablators in the past space mission mentioned above. The LATS is a carbon phenolic ablator fabricated by impregnating a phenolic resin into a felt made of carbon fibers.
Concept of thermal protection using a charring ablator is shown in Fig. 1 and described as follows:

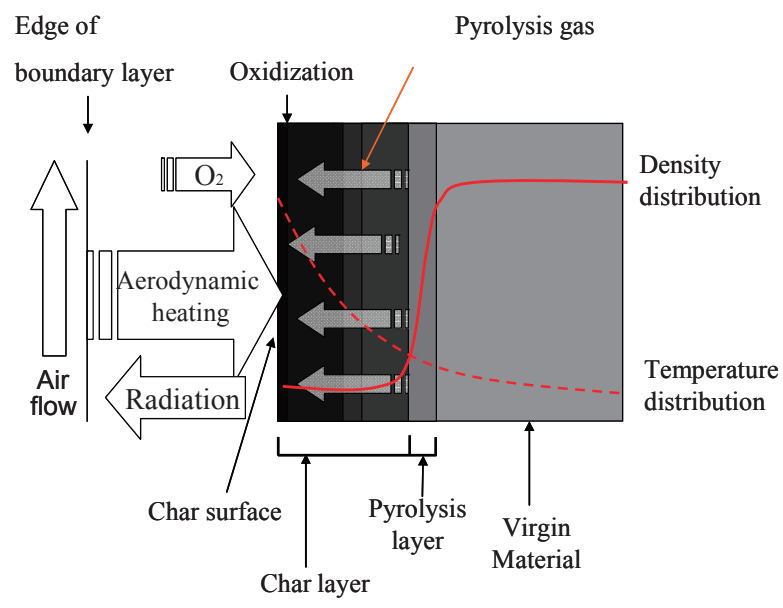

Fig. 1. Concept of charring ablation.

- When the ablator surface is heated and the temperature become high, pyrolysis reaction occurs in the resin of the ablator, pyrolysis gas is generated and the resin is carbonized. The carbonized resin forms the porous char layer with neighboring refractory reinforcement fiber, and the pyrolysis gas passes through the char layer and goes out from the char surface.

- When the pyrolysis gas passes through the char layer, heat 
energy is taken away from the char layer. The pyrolysis gas which is ejected from the surface blocks a part of the heat which enters the ablator at the surface.

- The surface of the char layer recedes due to the process of thermochemistry (e.g., oxidation, sublimation, melting, evaporation) and a mechanical processes (e.g. spallation). The gas which is formed by surface reaction blocks a part of the aerodynamic heating in a similar way to the pyrolysis gas.

- The radiation energy is emitted from the high temperature char surface.

In order to design the heat shield system, it is necessary to predict the thermal behavior of the ablator under severe aerodynamic heating environments during the earth re-entry or a planetary entry of the capsule by ablation analysis.

Until now, a lot of ablation analysis codes have been developed. Among them one-dimensional computational codes for ablation analysis have been widely used. ${ }^{7-9)}$ A new computational code for one-dimensional ablation analysis has been developed by some of the authors of this paper. As for a high density CFRP ablator, it was confirmed that onedimensional ablation analysis code was able to be applied to simulation of ablator thermal behavior in the arc-heated test environments. ${ }^{7)}$ On the other hand, concerning the low density LATS ablator that has been recently developed, the applicability of ablation analysis code has not yet been confirmed.

In this paper the outline of the computer code for charring ablation and thermal response analysis, which is developed for simulation of one-dimensional transient thermal behavior of charring materials, is briefly described. The mathematical model for the charring ablation code including basic equations and computational method of ablation analysis are shown. The calculated results of several thermal response problems are compared with the analytical solutions for the evaluation of the accuracy of the charring ablation code. Thermal behaviors and performance data of the LATS ablators were obtained by carrying out the arc-heated tests of the ablators. The validity of the mathematical model and the applicability of the one-dimensional ablation code are discussed based on the evaluation of the comparison between the results of arc-heated test and simulation of the LATS ablator.

\section{Mathematical Model of Charring Ablation}

The mathematical model of charring ablation which is used in the one-dimensional ablation analysis code is shown in the following. The mathematical model is similar to the one in Ref. 7), and the basic assumption, basic equations and boundary condition are briefly described.

2.1. Basic assumptions of the mathematical model of charring ablation

(a) This mathematical model treats one-dimensional unsteady state ablation phenomenon.

(b) One layer ablator is considered. (Ablator of multiple layers is not considered)

(c) The pyrolysis gas generated in the ablator moves to the surface without remaining there. When pyrolysis gas moves to the surface, the temperature of the gas is assumed to be equal to the temperature of the neighboring char.

(d) After the pyrolysis gas is ejected from the ablator surface, the pyrolysis gas is assumed chemically inert with respect to the gas in the boundary layer.

(e) All the char layer of ablator is assumed to be carbon, and the surface recession depends on the oxidation and sublimation only. Spallation ${ }^{*^{1)}}$ and coking ${ }^{*^{2)}}$ phenomina are not considered.

${ }^{* 1)}$ When the ablator is exposed to intense heating, a char layer is produced and the pyrolysis gas is generated. The char layer is subject to the pyrolysis gas pressure, the thermal stress, and the surface shear force by the high enthalpy flow. As a result, carbonaceous solid particles are ejected from the ablation surface into the flow. This phenomenon is called "Spallation". 10,11)

*2) "Coking" is a phenomenon that a solid carbon is deposited when the pyrolysis gas passes through the porous char layer to the surface. The coking phenomenon increases the density of the char layer near the surface of the heated material. ${ }^{12,13)}$

\subsection{Basic equations}

The basic equations about the charring ablation are well known. $^{7-9,14)}$ Among the basic equations that this analysis code uses, the in-depth energy equation of the ablator is expressed by

$\rho C_{p}\left(\frac{\partial T}{\partial t}\right)_{x}=\frac{\partial}{\partial x}\left(k \frac{\partial T}{\partial x}\right)_{t}+\Delta h_{p y r o}\left(\frac{\partial \rho}{\partial t}\right)_{y}+\dot{S} \rho C_{p}\left(\frac{\partial T}{\partial x}\right)_{t}+\dot{m}_{g}\left(\frac{\partial h_{g}}{\partial x}\right)_{t}$

where $x$ is the coordinate with the origin fixed to the surface which moves due to the surface recession, $y$ is the coordinate with the origin fixed to the ablator surface before heating, $\rho$ is the density $\left(\mathrm{kg} / \mathrm{m}^{3}\right), C_{p}$ is the specific heat $(\mathrm{J} / \mathrm{kg} / \mathrm{K}), T$ is the temperature $(\mathrm{K}), t$ is the time $(\mathrm{s}), k$ is the thermal conductivity $(\mathrm{W} / \mathrm{m} / \mathrm{K}), \Delta h_{\text {pyro }}$ is the heat of pyrolysis per produced gas of unit mass $(\mathrm{J} / \mathrm{kg}), \dot{S}$ is the surface recession rate $(\mathrm{m} / \mathrm{s}), \dot{m}_{g}$ is the gas flow rate $\left(\mathrm{kg} / \mathrm{m}^{2} / \mathrm{s}\right)$ (mass flux) and $h_{g}$ is the enthalpy of the pyrolysis gas $(\mathrm{J} / \mathrm{kg}) . k$ and $C_{p}$ is calculated by

$$
\begin{gathered}
k=k_{v} \omega+(1-\omega) k_{c h} \quad \omega=\left(\rho-\rho_{c h}\right) /\left(\rho_{v}-\rho_{c h}\right) \\
\rho C_{p}=\omega \rho_{v} C_{p v}+(1-\omega) \rho_{c h} C_{p c h}
\end{gathered}
$$

where $\rho_{v}, \rho_{c h}$ is the virgin and char density, $k_{v}, k_{c h}$ is the thermal conductivity of the virgin and char materials, and $C_{p v}$, $C_{p c h}$ is the specific heat of the virgin and char materials, respectively.

The equation of mass conservation when the ablator yields the pyrolysis gas and the Arrhenius type expression for the decomposition rate are described by the following equations, respectively

$$
\left(\partial \dot{m}_{g} / \partial \mathrm{y}\right)_{\mathrm{t}}=(\partial \rho / \partial t)_{\mathrm{y}}
$$




$$
\left(\frac{\partial \rho}{\partial t}\right)_{y}=-\sum_{k=1}^{N} A_{k} f_{k}\left(\rho_{v}-\rho_{c h}\right)\left(\frac{\rho-\rho_{c h}}{\rho_{v}-\rho_{c h}}\right)^{\mu_{\mathrm{k}}} \exp \left(-\frac{B_{k}}{T}\right)
$$

where $\mu_{k}$ is the reaction order, $A_{k}$ is the weighting factor, $f_{k}$ is the collision frequency $(1 / \mathrm{s}), B_{k}$ is the activation temperature (K). These values are assumed to be constant.

\subsection{Boundary condition}

The energy balance at the ablator surface yields the surface boundary condition. In consideration of aerodynamic heating, block effect of heating due to the gas ejection, radiation cooling, enthalpy change when the char surface recedes, enthalpy change of pyrolysis gas and the heat conduction in the ablator, the energy balance equation is obtained and shown below, ${ }^{14)}$

$\dot{q}_{n e t}=\dot{q}_{c w}\left(1-h_{w} / h_{r}\right) \phi_{b l o w}-\varepsilon \sigma\left(T_{w}{ }^{4}-T_{r e f}{ }^{4}\right)-\dot{m}_{a b}\left(h_{w}-h_{u}\right)$

where $\dot{q}_{\text {net }}$ is the net heat flux conducted into the ablator $\left(\mathrm{W} / \mathrm{m}^{2}\right), \dot{q}_{c w}$ is the cold wall convective heat flux $\left(\mathrm{W} / \mathrm{m}^{2}\right), h_{w}$ is the enthalpy of the gas adjacent to the surface, $h_{r}$ is the recovery enthalpy of the flow, $\phi_{\text {blow }}$ is the blowing correction factor, $\varepsilon$ is the emissivity, $\sigma$ is the Stefan-Boltzmann constant $\left(5.670 \times 10^{-8} \mathrm{~W} / \mathrm{m}^{2} / \mathrm{K}^{4}\right), T_{w}$ is the temperature of the char surface $(\mathrm{K}), T_{\text {ref }}$ is $300 \mathrm{~K}, \quad \dot{m}_{a b}\left(=\rho_{c h} \dot{S}\right)$ is the mass flux due to the thermochemical ablation of the char $\left(\mathrm{kg} / \mathrm{m}^{2} / \mathrm{s}\right)$, and $h_{u}$ is the enthalpy of the char at the surface $(\mathrm{J} / \mathrm{kg})$.

\section{Computational Procedure}

The temperature and the density distribution in the ablator are obtained based on Eq. (1) (energy equation), Eq. (2) (mass conservation) and Eq. (3) (thermal decomposition rate) by the use of the finite difference method.

The analysis model for the finite difference method is shown in Fig. 2. The surface node width is half of the other node width. The representation point of the surface node is located on the surface. The last node of the ablator shrinks according to the surface recession. If the last node width becomes less than the predetermined width, the last node and



Fig. 2. Analysis model.

the adjacent node join and become a new last node. This means that the number of total nodes decreases as the surface recession proceeds. Compared with the temperature

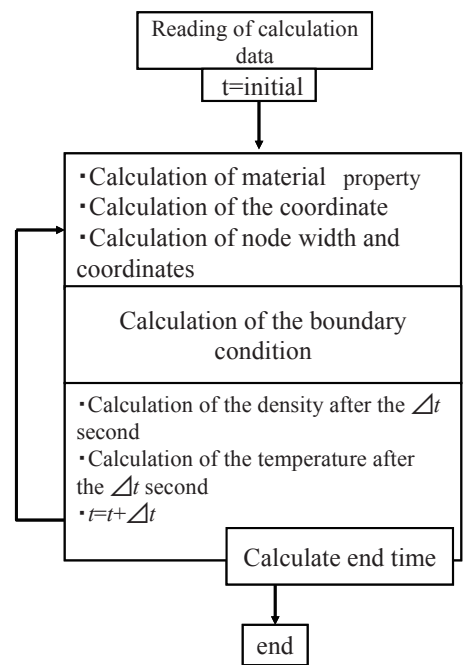

Fig. 3. Flow chart of ablation analysis program.

distribution, the density gradient in the ablator is higher in a narrow region and more number of division is needed for the accurate density calculation. For this reason, each node is divided into a certain number of nodelets, which is shown in Fig. 2.

The simple flow chart of the ablation analysis program for the calculation of the temperature and density distribution in the ablator is shown in Fig. 3. The expression for the calculation of the nodelet density at the time $=t+\Delta t$ is given by,

$$
\begin{gathered}
\frac{\rho_{n, j}^{\prime}-\rho_{n, j}}{\Delta t}=\frac{\left(\rho_{n, j+1}-\rho_{n, j}\right) \dot{S}}{\delta_{n, j}}+\left(\frac{\partial \rho_{n, j}}{\partial t}\right)_{d} \\
\left(\frac{\partial \rho_{n, j}}{\partial t}\right)_{d}=-\sum_{k=1}^{N} A_{k} f_{k}\left(\rho_{v}-\rho_{c h}\right)\left(\frac{\rho_{n, j}-\rho_{c h}}{\rho_{v}-\rho_{c h}}\right)^{\mu_{\mathrm{k}}} \exp \left(-\frac{B_{k}}{T}\right)
\end{gathered}
$$

where parameters without superscript ' denotes the value at time $t$, superscript ' denotes the value at time of $t+\Delta t, \rho_{n, j}$ denotes the density of $j^{\text {th }}$ nodelet of $n^{\text {th }}$ node, $\Delta t$ is the time increment, $n$ is the node number, $j$ is the nodelet number, $\delta_{n, j}$ is the width of $j^{\text {th }}$ nodelet of $n^{\text {th }}$ node, and subscript ${ }_{d}$ denotes the value with respect to the $y$ axis.

Temperature of each node is calculated by the explicit finite difference formula based on the energy equation. Finite difference form of the $n^{\text {th }}$ node in the ablator is shown below,

$$
\begin{aligned}
\left(\rho C_{p}\right)_{n} \frac{\left(T_{n}^{\prime}-T_{n}\right)}{\triangle t}=\frac{1}{\delta_{n}}\left(\frac{T_{n-1}-T_{n}}{\frac{\delta_{n-1}}{2 k_{n-1}}+\frac{\delta_{n}}{2 k_{n}}-\frac{T_{n}-T_{n+1}}{\delta_{n}}+\frac{\delta_{n+1}}{2 k_{n+1}}}\right)+\operatorname{hppyr}\left(\frac{\partial \rho_{n}}{\partial t}\right)_{y} \\
+\dot{S}(t)\left(\rho C_{p}\right)_{n} \frac{1}{2}\left[\frac{T_{n}-T_{n-1}}{\delta_{n-1} / 2+\delta_{n} / 2}+\frac{T_{n+1}-T_{n}}{\delta_{n} / 2+\delta_{n+1} / 2}\right] \\
+\dot{m}_{g_{n}} \frac{1}{2}\left[\frac{h_{g_{n}}-h_{g_{n-1}}}{\delta_{n-1} / 2+\delta_{n} / 2}+\frac{h_{g_{(n+1)}}-h_{g_{n}}}{\delta_{n} / 2+\delta_{n+1} / 2}\right]
\end{aligned}
$$


where $\delta_{n}$ denotes the width of the $n^{\text {th }}$ node and subscript $n$ denotes $n^{\text {th }}$ node.

\section{Comparison Between Numerical and Analytical Solutions}

In order to confirm the reliability of the ablation analysis program, simulation results of several thermal response problems that are obtained using the charring ablation analysis code are compared with analytical solutions. Examples of the comparison are shown below.

\subsection{Quasi steady state heat conduction problem of a} semi-infinite solid (with surface recession and pyrolysis)

Heat conduction problem in a semi-infinite solid, with the boundary condition of the fixed surface temperature of 3500 $\mathrm{K}$ and uniform initial temperature of $300 \mathrm{~K}$ are considered. The surface recession is assumed constant. Thermal decomposition inside the solid is also assumed. The exact quasi-steady analytical solution is calculated based on the equation of Ref. 15). As for the numerical calculation using the analysis code, the thickness of the ablator is set to be $0.4 \mathrm{~m}$, which is much thicker than the usual ablator thickness. The thickness of a large value is selected to treat a semi-infinite solid in the program and to avoid disappearance of the solid

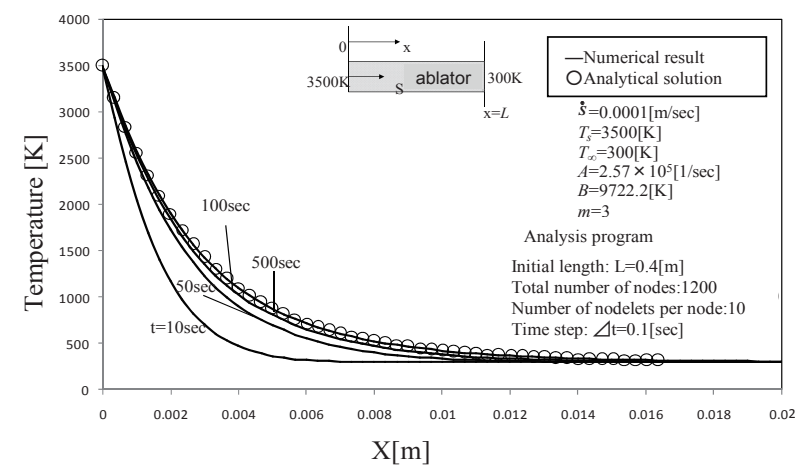

Fig. 4. Comparison of temperature between the results of numerical and analytical calculation.

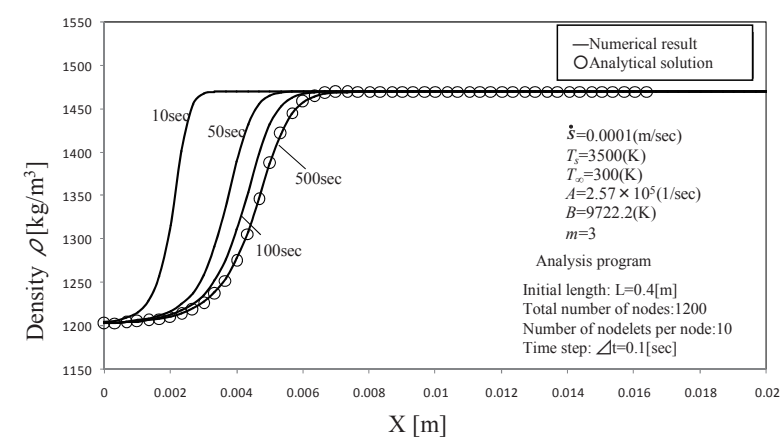

Fig. 5. Comparison of density between the results of numerical and analytical calculation.

due to the surface recession in the calculation. The virgin density is set to be $1470 \mathrm{~kg} / \mathrm{m}^{3}$ and the char density is set to be $1200 \mathrm{~kg} / \mathrm{m}^{3}$. The calculation was carried out with the time step of $\Delta t=0.1 \mathrm{sec}$, total node number of 1200 and nodelet number

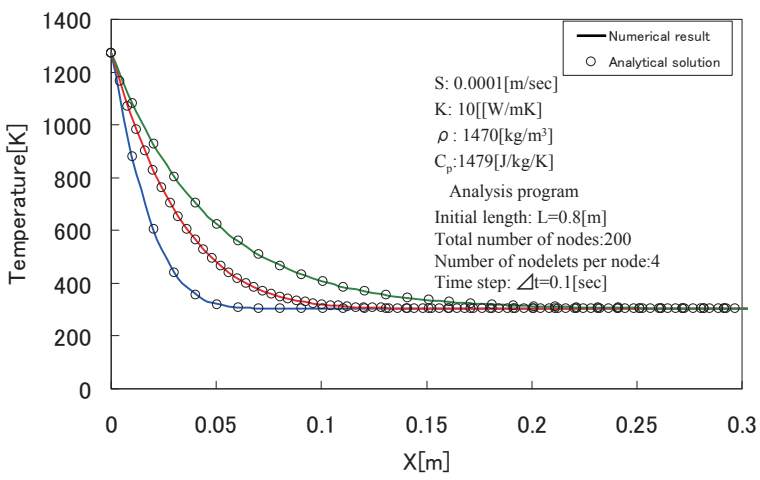

Fig. 6. Comparison of temperature between the numerical and analytical solution.

of 10 per each node. As for the thermal properties used for the calculation, constant values of $0.5 \mathrm{~W} / \mathrm{m} / \mathrm{K}$ for the thermal conductivity, $1046.5 \mathrm{~J} / \mathrm{kg} / \mathrm{K}$ for the specific heat of the solid and $1674.4 \mathrm{~J} / \mathrm{kg} / \mathrm{K}$ for the specific heat of the pyrolysis gas were used, respectively.

Comparison of numerical solution of analysis program and the analytical solution are shown in Figs. 4 and 5, respectively. Fig. 4 shows the temperature distribution of the numerical result of the analysis program at the time of 10, 50, 100 and $500 \mathrm{~s}$ compared with the quasi-steady state analytical solution. As the time increases, the temperature calculated by the analysis program approaches the analytical solution, and at the time of $500 \mathrm{~s}$ the temperature agrees well with that of the analytical solution. Fig. 5 shows the density distribution of the numerical calculation by the analysis program at the time of 10, 50, 100 and $500 \mathrm{~s}$, compared with the quasi-steady state analytical solution. In a similar way to the case of the temperature distribution, the density distribution by the numerical calculation approaches the analytical solution, and at the time of $500 \mathrm{~s}$, the density agrees well with the analytical solution. Steep density gradient is seen in the neighborhood of the surface.

4.2. Unsteady state heat conduction problem of a semiinfinite solid (with surface recession and no pyrolysis)

Heat conduction problem in a semi-infinite solid with the boundary condition of the fixed surface temperature of $1300 \mathrm{~K}$ and uniform initial temperature of $300 \mathrm{~K}$ is considered. In the same way as in 4.1 the surface recession is assumed constant. In this case thermal decomposition is not considered. The exact transient analytical solution is calculated based on the equation of Ref. 16). The numerical solution by the analysis code is calculated in a similar way to 4.1 .

Fig. 6 shows the temperature distributions of numerical results of the analysis program compared with the analytical solution at three kinds of times. It is seen that each of the temperature distributions calculated by the analysis program agrees well with the analytical solution at each time, respectively.

Based on the results mentioned above, the validity of the simulation program is confirmed. 


\section{Comparison between the Results of Arc-heated Test and Simulation.}

\subsection{Arc-heated test}

Arc-heated tests of the new ultra light density phenolic carbon ablator called LATS (Lightweight Ablator series for Transfer Vehicle) were carried out using the $750 \mathrm{~kW}$ arc heating wind tunnel of Japan Aerospace Exploration Agency (JAXA). Each ablator test model had a cylindrical shape and the heating surface of the model was flat. Two kinds of test models (type A and type B) were used. The type A test model was $34 \mathrm{~mm}$ in diameter and $20 \mathrm{~mm}$ in thickness. The side of

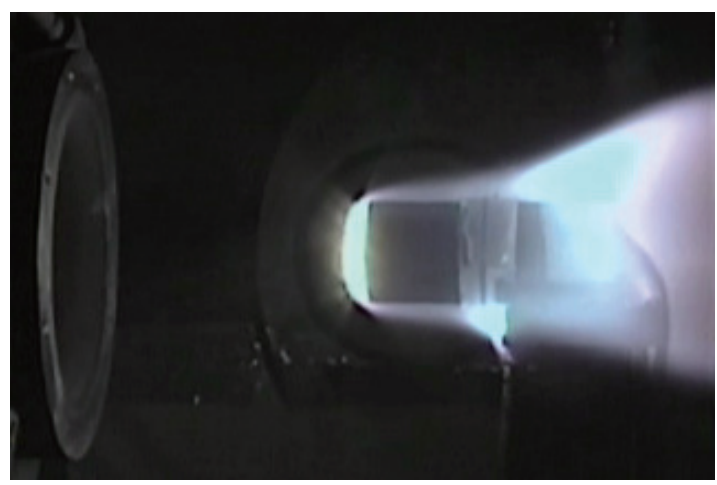

Fig. 7. Test model during arc-heated test.

the type A ablator was covered by an ablator holder of $40 \mathrm{~mm}$ outer diameter made of CFRP material. The purpose of the holder was to protect the ablator model from side heating so that one dimensional heating environment could be obtained. The outer side of the holder was protected by glass cloth

Table 1. Heating conditions and test model.

\begin{tabular}{|c|c|c|c|c|c|c|}
\hline \multicolumn{4}{|c|}{ Heat condition } & \multicolumn{3}{|c|}{ Test model } \\
\hline $\begin{array}{c}\text { Heating } \\
\text { rate } \\
\mathrm{MW} / \mathrm{m}^{2}\end{array}$ & $\begin{array}{c}\text { Heating } \\
\text { time } \\
\mathrm{s}\end{array}$ & $\begin{array}{c}\text { Impact } \\
\text { pressure } \\
\mathrm{Pa}\end{array}$ & $\begin{array}{c}\text { Flow } \\
\text { enthalpy } \\
\mathrm{MJ} / \mathrm{kg}\end{array}$ & $\begin{array}{c}\text { Dia } \\
\mathrm{mm}\end{array}$ & $\begin{array}{c}\text { Length } \\
\mathrm{mm}\end{array}$ & $\begin{array}{c}\text { Density } \\
\mathrm{kg} / \mathrm{m}^{3}\end{array}$ \\
\cline { 1 - 6 } 0.97 & \multirow{2}{*}{60} & 1930 & 12.8 & $\begin{array}{c}\text { type A } \\
34\end{array}$ & $\begin{array}{c}\text { type A } \\
20\end{array}$ & $\begin{array}{c}\text { type A } \\
238 \sim 717 \\
1.98\end{array}$ \\
\cline { 3 - 4 } & 4250 & 18.8 & $\begin{array}{c}\text { type B } \\
40\end{array}$ & $\begin{array}{c}\text { type B } \\
40\end{array}$ & $\begin{array}{c}\text { type B } \\
285 \sim 390\end{array}$ \\
\hline
\end{tabular}

material. The type B test model was $40 \mathrm{~mm}$ in diameter and $40 \mathrm{~mm}$ in thickness. The outer side of the B type ablator model was not protected from the side heating. Each test model was installed in the mount of the facility.

The tests were carried out with two kinds of heating conditions: one is the low heating rate of $0.97 \mathrm{MW} / \mathrm{m}^{2}$, and the other is the high heating rate of $1.98 \mathrm{MW} / \mathrm{m}^{2}$, where air was used as a working gas. The heating time was mainly $60 \mathrm{~s}$. The time history of the in-depth temperature was measured for $600 \mathrm{~s}$, where the start time of the heating corresponds to $0 \mathrm{~s}$. A test model during the arc-heated test is shown in Fig. 7. The flat surface of the test model is heated by the high-enthalpy flow, which is ejected from the nozzle on the left of the model in the figure. The diameter and length of the test model are $40 \mathrm{~mm} \phi$ and $40 \mathrm{~mm}$, respectively.

The surface temperature of the test model was measured by the two-color pyrometer and the in-depth temperature was measured by $\mathrm{K}$ type thermocouples installed in the ablator. The surface recession of each ablator model was also measured.

The heating conditions and test model data are shown in Table 1.

\subsection{Input data for calculation}

The input data for the calculation of the thermal behavior of the test model using the one-dimensional ablation analysis program include parameters such as heating environment conditions, ablator thickness and thermal properties of the materials. These parameters were set based on the measured data and the literature data. The cold wall heating rate, air enthalpy and the impact pressure were set based on the measured data during the heating test. The thickness of the model and the virgin density $\rho_{v}$ of the ablator are set based on the measurement of each model. The char density for each ablator model is calculated based on the TGA data of the LATS ablator with the virgin density of about 300, 500, $700 \mathrm{~kg} / \mathrm{m}^{3}$. Generally the surface emissivity of the char material is dependent on the surface temperature. ${ }^{4,17)}$ However, a lot of ablation analyses have been carried out using a constant value of the emissivity. For example, the values of $0.8^{18)}, 0.85^{3,14,19-21)}$ and $0.9^{22)}$ are used, respectively. In this paper, the emissivity of the char surface was set to be 0.85 .

The reference value of thermal conductivity of the virgin material $k_{v \text { ref }}$ is constructed of the measured value of the LATS materials with the density of about $300 \mathrm{~kg} / \mathrm{m}^{3}$, using a steady-state method with the temperature range from RT to $573 \mathrm{~K}\left(300{ }^{\circ} \mathrm{C}\right)$, combined with the literature data ${ }^{4)}$ of the low density (about $300 \mathrm{~kg} / \mathrm{m}^{3}$ ) ablator (PICA) multiplied by a constant value, $C^{*} k_{v \mathrm{PICA}}(T)$, where $k_{v \mathrm{PICA}}(T)$ is the thermal conductivity of the PICA and $C$ is a constant value that is determined so that the two data are smoothly connected. The reference value of thermal conductivity of the char material $k_{c h r e f}$ is assumed to be the same as that of the virgin material $k_{\text {vref }}\left(k_{\text {chref }}=k_{\text {vef }}\right)$.

The specific heat of the char material $C_{p c h}$ is based on the data of Ref. 14) and is expressed by

$$
c_{p c h}=C_{\infty} \frac{T}{\sqrt{T^{2}+D^{2}}}
$$

where $T$ is the temperature (K), $C_{\infty}=2.3 \times 10^{3} \mathrm{~J} /(\mathrm{kg} \mathrm{K})$, and $D$ $=800 \mathrm{~K}$. The specific heat of the virgin material $C_{p v}$ is constructed of the measured data with the temperature range of RT to $300{ }^{\circ} \mathrm{C}(573 \mathrm{~K})$, combined with Eq. (10), in which the connection is made smoothly.

Specific heat of the pyrolysis gas $C_{p g}$ is set to be a constant value of $1674.6 \mathrm{~J} /(\mathrm{kg} \cdot \mathrm{K}){ }^{21)}$ The heat of pyrolysis per gas produced $\Delta h_{\text {pyro }}$ is set to be $3.313 \times 10^{5} \mathrm{~J} / \mathrm{kg}(79.1 \mathrm{cal} / \mathrm{g})$, which is determined considering the measured and the literature data. Coefficients in the Arrhenius equation (Eq. (5)) are set based on the TGA data of the LATS ablator. ${ }^{23)}$ The values of $N=2, A_{1}=0.1, f_{1}=3.5 \times 10^{9} 1 / \mathrm{s}, B_{1}=1.1 * 10^{4} \mathrm{~K}$, 
$\mu_{1}=100.0, A_{2}=0.9, f_{2}=7.0^{*} 10^{3} 1 / \mathrm{s}, B_{2}=1.1 \times 10^{4} \mathrm{~K}, \mu_{2}=3$ are used in the calculation.

\subsection{Tuning of input parameters to improve simulation accuracy}

Among the input data for the simulation of the LATS ablator mentioned above, thermal conductivity values would have a largest effect on the temperature calculation. However, we have not yet obtained a sufficient amount of reliable measured data of thermal conductivity for the LATS material, especially in a high temperature region. Moreover the thermal conductivity not only depends on the temperature but also on the ablator density. ${ }^{23)}$ In order to overcome this difficulty, tuning of the thermal conductivity was carried out for the simulation. The procedure of the tuning method is shown as follows:

(1) Multiply the thermal conductivity data $k_{v r e f}$ and $k_{\text {chref }}$ by appropriate constant values of the tuning coefficients $C_{1}, C_{2}$ to yield a new set of thermal conductivity $C_{1} * k_{\text {vref }}$ and $C_{2} * k_{\text {chref. }}$

(2) Using the new set of $C_{1} * k_{\text {vref }}$ and $C_{2} * k_{\text {chref, }}$, we carry out the ablation analysis.

(3) If the calculated temperatures do not agree well with the measured results, the tuning coefficients $C_{1}, C_{2}$ are changed and ablation analysis is carried out using the changed values of $C_{1}, C_{2}$.

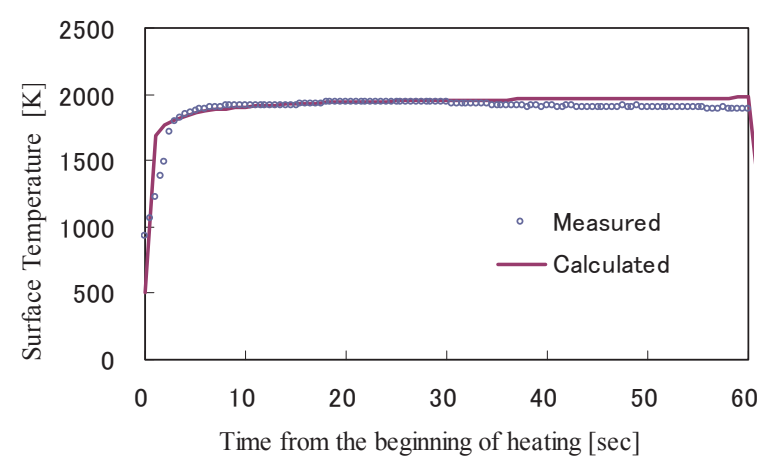

Fig. 9a. Comparison of surface temperature. $\left(\rho_{v}=264.0 \mathrm{~kg} / \mathrm{m}^{3}, \dot{q}=0.97 \mathrm{MW} / \mathrm{m}^{2}, C_{1}=0.925, C_{2}=1.05\right)$

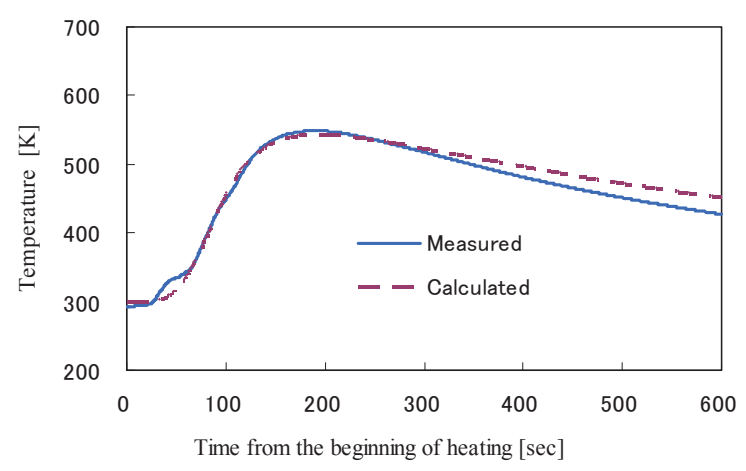

Fig. 9b. Comparison of back surface temperature. $\left(\rho_{v}=264.0 \mathrm{~kg} / \mathrm{m}^{3}, \dot{q}=0.97 \mathrm{MW} / \mathrm{m}^{2}, C_{1}=0.925, C_{2}=1.05\right)$
(4)The procedure (3) is continued until we have a good agreement between calculation and measurement.

(5) When the calculated temperature agrees well with the measured temperature, the tuning coefficients $C_{1}, C_{2}$ are finally determined.

\subsection{Comparison of temperature history}

Figures $9 \mathrm{a}$ and $9 \mathrm{~b}$ show the comparison between the measured and calculated values of surface temperature and back surface temperature of the A type model $(34 \mathrm{~mm}$ in diameter and $20 \mathrm{~mm}$ in thickness) with the virgin density of $264.0 \mathrm{~kg} / \mathrm{m}^{3}$. The cold wall heating rate is $0.97 \mathrm{MW} / \mathrm{m}^{2}$ with the heating time of $60 \mathrm{~s}$. In the numerical calculation by the analysis program, the thermal conductivities were tuned for good agreement, and the tuning coefficients of the test model were determined to be $C_{1}=0.925, C_{2}=1.05$. In Fig. $9 \mathrm{a}$, it is seen that the surface temperature rises rapidly to about $1900 \mathrm{~K}$ in about 5 s, and slightly rises gradually. In Fig. $9 \mathrm{~b}$, it is seen that the back surface $(20 \mathrm{~mm}$ from the heating surface) temperature rises to about $550 \mathrm{~K}$ in about $180 \mathrm{~s}$, and gradually decreases. It is seen that the simulation results of the surface and the back surface temperature history by the analysis program agree well with the measured results.

Figures $10 \mathrm{a}$ and $10 \mathrm{~b}$ show the comparison between the measured and calculated values of surface and back surface temperature of the A type model with the virgin density of

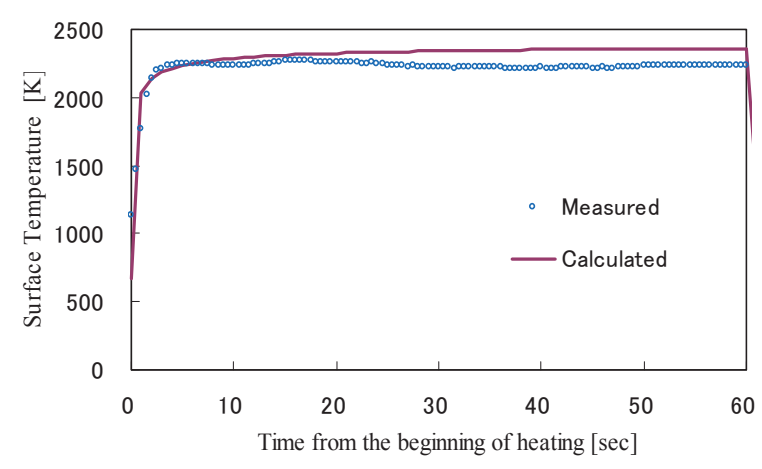

Fig. 10a. Comparison of surface temperature. $\left(\rho_{v}=287.2 \mathrm{~kg} / \mathrm{m}^{3}, \quad \dot{q}=1.98 \mathrm{MW} / \mathrm{m}^{2}, C_{1}=1.3, C_{2}=1.2\right)$

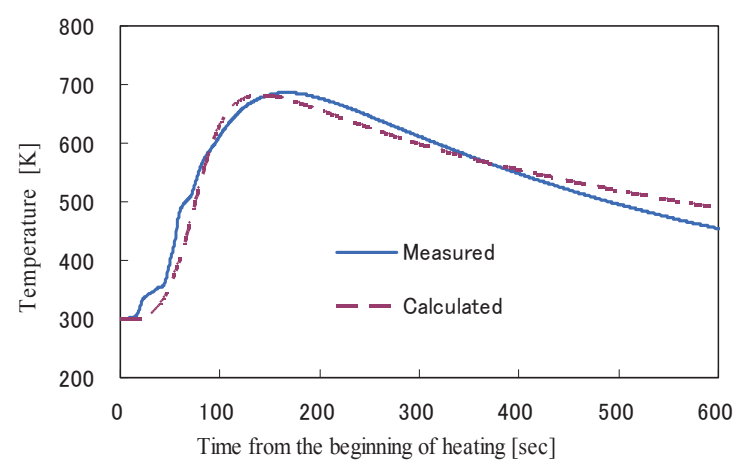

Fig. 10b. Comparison of back surface temperature. $\left(\rho_{v}=287.2 \mathrm{~kg} / \mathrm{m}^{3}, \dot{q}=1.98 \mathrm{MW} / \mathrm{m}^{2}, C_{1}=1.3, C_{2}=1.2\right)$ 


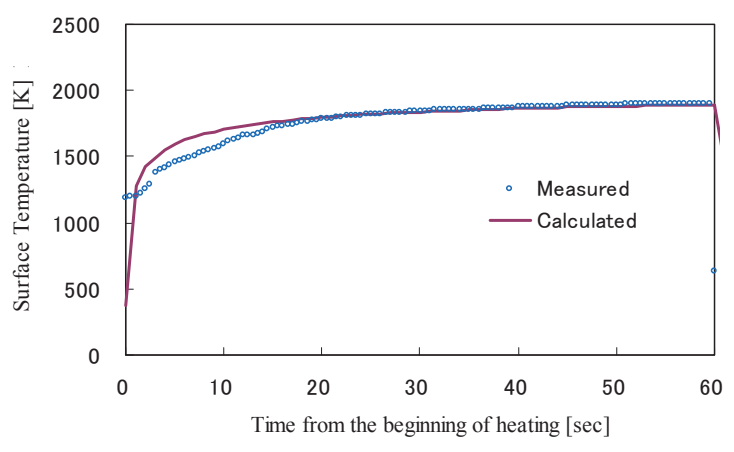

Fig. 11a. Comparison of surface temperature.

$\left(\rho_{\mathrm{v}}=693.5 \mathrm{~kg} / \mathrm{m}^{3}, \dot{q}=0.97 \mathrm{MW} / \mathrm{m}^{2}, C_{1}=2.35, C_{2}=2.5\right)$

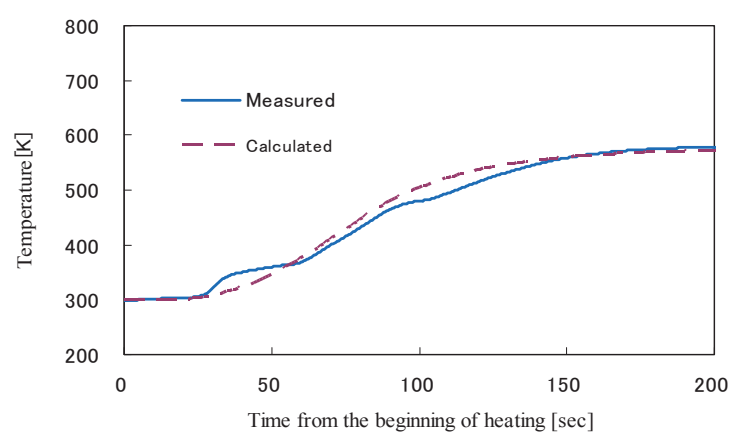

Fig. 11b. Comparison of in-depth temperature. (15mm from the surface)

$\left(\rho_{\mathrm{v}}=693.5 \mathrm{~kg} / \mathrm{m}^{3}, \dot{q}=0.97 \mathrm{MW} / \mathrm{m}^{2}, C_{1}=2.35, C_{2}=2.5\right)$

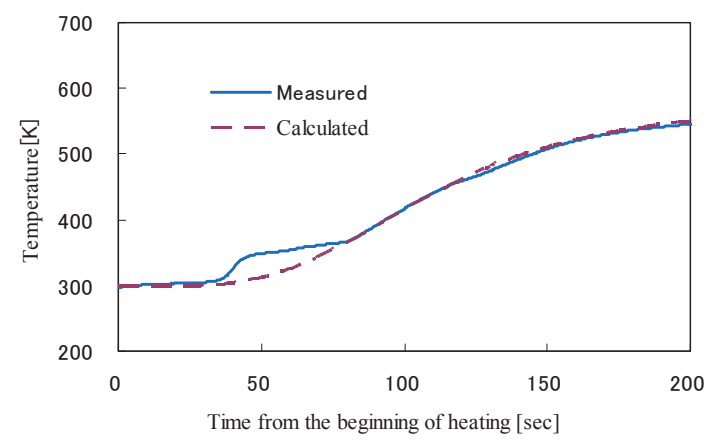

Fig. 11c. Comparison of back surface temperature. $\left(\rho_{\mathrm{v}}=693.5 \mathrm{~kg} / \mathrm{m}^{3}, \dot{q}=0.97 \mathrm{MW} / \mathrm{m}^{2}, C_{1}=2.35, C_{2}=2.5\right)$

$287.2 \mathrm{~kg} / \mathrm{m}^{3}$. The cold wall heating rate is $1.98 \mathrm{MW} / \mathrm{m}^{2}$ with the heating time of $60 \mathrm{~s}$. In the numerical calculation by the analysis program, the thermal conductivities were tuned, and the tuning coefficients of $C_{1}=1.3, C_{2}=1.2$ were obtained. In Fig. $10 \mathrm{~b}$, it is seen that the back surface $(20 \mathrm{~mm}$ from the heating surface) temperature rises to about $700 \mathrm{~K}$ in about 180 $\mathrm{s}$, and gradually decreases. It is seen that the simulation results of the front and back surface temperature history by the analysis program agree well with the measured results.

Figures 11a-11c show the comparison between the

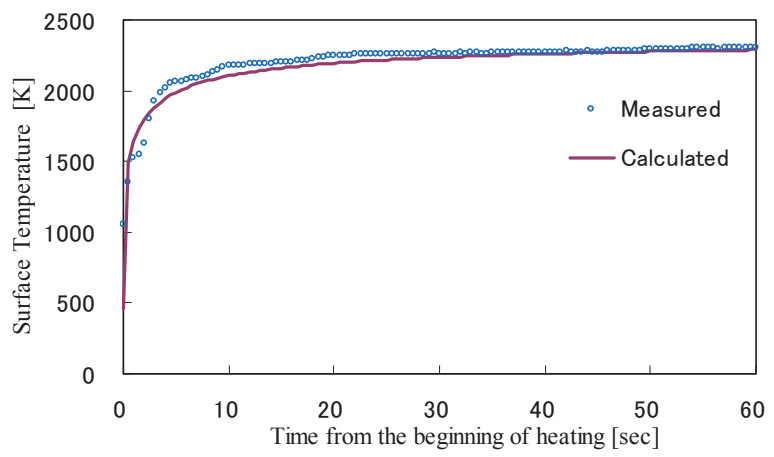

Fig. 12a. Comparison of surface temperature. $\left(\rho_{\mathrm{v}}=688.8 \mathrm{~kg} / \mathrm{m}^{3}, \dot{q}=1.98 \mathrm{MW} / \mathrm{m}^{2}, C_{1}=2.5, C_{2}=2.8\right)$

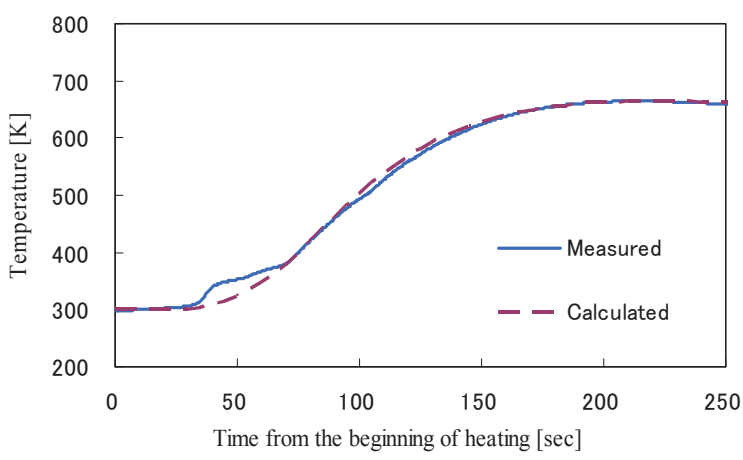

Fig. 12b. Comparison of back surface temperature. $\left(\rho_{\mathrm{v}}=688.8 \mathrm{~kg} / \mathrm{m}^{3}, \dot{q}=1.98 \mathrm{MW} / \mathrm{m}^{2}, C_{1}=2.5, C_{2}=2.8\right)$

measured and calculated values of the front surface, in-depth (15 $\mathrm{mm}$ from the front surface) and back surface temperature (20 $\mathrm{mm}$ from the front surface). The test model is the A type and the virgin density of the model is $693.5 \mathrm{~kg} / \mathrm{m}^{3}$, which is rather high compared with that of low density value of about $300 \mathrm{~kg} / \mathrm{m}^{3}$. The cold wall heating rate is $0.97 \mathrm{MW} / \mathrm{m}^{2}$ with the heating time of $60 \mathrm{~s}$. In the numerical calculation by the analysis program, the thermal conductivities were tuned, and the tuning coefficients of $C_{1}=2.35, C_{2}=2.5$ were obtained. The tuning coefficients obtained are larger than those of the lower density ablator mentioned above, which means that the thermal conductivity of higher density ablator is larger than that of the lower density ablator. This tendency conforms to the measured results of thermal conductivity of the LATS. ${ }^{23)}$ It is seen that the simulation results of the surface, in-depth and the back surface temperature history by the analysis program agree well with the measured results within the time ranges in these figures.

Figures $12 \mathrm{a}$ and $12 \mathrm{~b}$ show the comparison between the measured and calculated values of the front surface and back surface temperature (20 $\mathrm{mm}$ from the front surface) of the A type model with the virgin density of $688.8 \mathrm{~kg} / \mathrm{m}^{3}$, which is also rather high compared with that of low density value of about $300 \mathrm{~kg} / \mathrm{m}^{3}$. The cold wall heating rate is $1.98 \mathrm{MW} / \mathrm{m}^{2}$ with the heating time of $60 \mathrm{~s}$. In the numerical calculation by the analysis program, the thermal conductivities were tuned, and the tuning coefficients of $C_{1}=2.5 C_{2}=2.8$ were obtained. 
The tuning coefficients are about the same as those of the LATS ablator with the density of $693.5 \mathrm{~kg} / \mathrm{m}^{3}$, which implies that the thermal conductivity of the higher density ablator $\left(693.5 \mathrm{~kg} / \mathrm{m}^{3}, 688.8 \mathrm{~kg} / \mathrm{m}^{3}\right)$ is about the same. It is seen that the simulation results of the surface and the back surface temperature history by the analysis program agree well with the measured results within the time ranges in these figures.

In Figs. 9a-12b in this section, some discrepancies between the measured and the calculated results are seen. Reasons for these discrepancies would include the following:

(1) Mathematical model of charring ablation

The mathematical model described in Chapter 2 does not perfectly describe the real ablation phenomenon.

\section{(2) Three-dimensional heat flow}

Whereas this model treats one-dimensional ablation phenomenon, the heating test of the ablator includes threedimensional phenomenon (for example, heating and cooling through the side wall of the ablator in the radial direction would influence the thermal behavior of the ablator).

\section{(3) Material property}

In this paper material property data are used in the calculation of ablation behavior. Whereas some measured values are used for the material property data, a large part of the data are predicted values based on the literature and so on. Increasing the measured values for the calculation would increase the calculation accuracy.

(4) Dispersion of the material property

Material properties for each ablator model would have different values due to the dispersion of the material properties. This could be the cause of the discrepancies.

\subsection{Comparison of surface recession}

Figure 13 shows the measured relation between the char mass loss due to the surface recession, $M_{a b} \mathrm{~kg} / \mathrm{m}^{2}\left(M_{a b}=S \rho_{c h}, S\right.$ : surface recession $(\mathrm{m}), \rho_{c h}$ : char density $\left.\left(\mathrm{kg} / \mathrm{m}^{3}\right)\right)$ and the total heat divided by the flow enthalpy, $Q / h_{\mathrm{r}} \mathrm{kg} / \mathrm{m}^{2}(Q=q \cdot t, q$ : heating $\operatorname{rate}\left(\mathrm{W} / \mathrm{m}^{2}\right), t$ : heating time $(\mathrm{s}), h_{\mathrm{r}}$ : air enthalpy $\left.(\mathrm{J} / \mathrm{kg})\right)$, which is compared with the calculated relation by the analysis program. In Fig.13, the measured data of B type model are plotted. $M_{a b}$ data of the high density ablator ${ }^{7)}\left(\rho_{v}=1460 \mathrm{~kg} / \mathrm{m}^{3}\right)$ due to surface recession are also included in the figure. It is seen that the relation is nearly linear and the measured data also agree well with the calculated data.

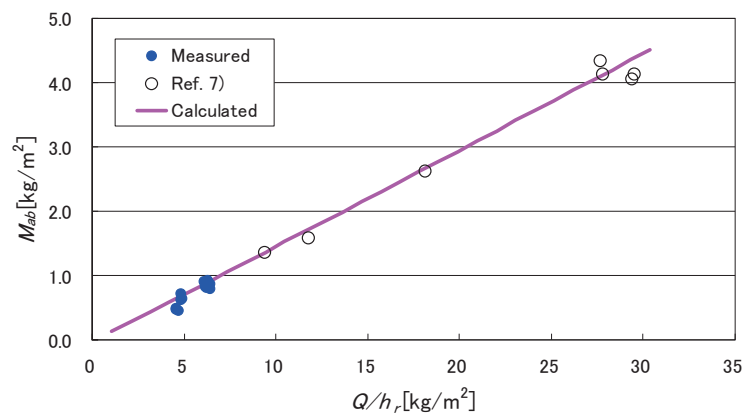

Fig. 13. Relation between $Q / h_{r}\left[\mathrm{~kg} / \mathrm{m}^{2}\right]$ and $M_{a b}\left[\mathrm{~kg} / \mathrm{m}^{2}\right]$.

\subsection{Improvement of the accuracy of the simulation}

As shown in the previous section, calculated results of the surface temperature, back surface temperature and in-depth temperature near the back surface agree well with the measured results within the time ranges in the figures. Calculated surface mass loss values agree with the measured results. However, as for the in-depth temperature, agreement was not so good when the distance from the back surface becomes large. (This tendency is not discussed in the previous section.) Heat flow not only in the axial direction but also in the radial direction would exist, which would decrease the simulation accuracy. So, the improvement of the simulation accuracy would be necessary.

In order to improve the accuracy of the simulation by the analysis program, the following are needed.

- Use of measured thermal property data of the material for simulation (especially thermal conductivity in the high temperature region).

- Comparison of the calculated and measured total mass loss data.

- Measurement of the density distribution of the model after the heating test and comparison of the measured and calculated density distribution.

- Ablation analysis in which the heat flow in the radial direction as well as in the axial direction is considered.

From the obtained results of this research, within the limited range of parameters with which tests and calculations were carried out, it seems that the mathematical model including the basic assumptions and equations in chapter 2 can be applied to the calculation of ablation behavior of the ultra light weight phenolic carbon ablator.

\section{Conclusions}

The computer code for charring ablator and thermal response analysis is newly developed for simulation of one-dimensional transient thermal behavior of charring ablation materials. Calculated results by the analysis program are compared with the arc-heated test results of the ultra light weight phenolic carbon ablator (LATS). The applicability of the ablation analysis code to the low density LATS ablator is evaluated. Main conclusions are described as follows:

(1) Numerical results by the newly developed analysis program using the ablation mathematical model agreed well with the analytical solutions.

(2) The simulation results of the surface and back surface temperature including the in-depth temperature near the back surface for the LATS ablator by the use of the tuning of thermal conductivity agreed well with the measured results.

(3) The measured relation between the char mass loss due to the surface recession and the total heat divided by the flow enthalpy agreed well with the calculated data. The relation is nearly linear.

(4) From (1) to (3), it seems that the one-dimensional mathematical model of ablation can be applied to the 
ablation analysis of the low density LATS ablator.

(5) In order to improve the accuracy of the simulation, use of the reliable measured data of thermal conductivity of the material for simulation is needed. Simulation in which the heat flow in the radial direction as well as in the axial direction is considered might improve the simulation accuracy. Comparison of measured data of total mass loss and density distribution with the calculated values are also needed in future work.

\section{Acknowledgement}

The authors are deeply grateful to graduate student Mr. Kanada of Aichi University of Technology for their support of this study, and to Mr. Inoue and others of Nagoya University who worked together during heating tests of the ablators. Moreover the author would like to express their gratitude to the operators of AES who supported the arc-heated test.

\section{References}

1) Kato, S., Sakata, R., Kanno, Y., Uto, M., Okuyama, K., Uegaki, E., Shingu, S., Ijichi, K. and Inatani, Y.: Development of USERS/REM Heat Shield System and its Evaluation after Re-entry, ISTS2004-e-36, Proceedings of the 24th International Symposium on Space Technology and Science (Selected Papers), Miyazaki, Japan, 2004, pp. 621-628.

2) Yamada, T., Ishii, N. and Inatani, Y.: Post Flight Analysis of the Hayabusa Sample Return Capsule, 2011-def-03, 28th International Symposium on Space Technology and Science $\left(28^{\text {th }}\right.$ ISTS), 5-12 June, Okinawa Prefecture, Japan.

3) Milos, F. S., Chen, Y.-K. and Squire T. H.: Analysis of Galileo Probe Heat Shield Ablation and Temperature Data: Ablation and Thermal Response Program for Spacecraft Heatshield Analysis, Journal of Spacecraft and Rockets, 36, No. 3 (1999), pp. 298-306.

4) Tran, H., Johnson, C., Rasky, D., Hui, F., Chan, Y. K. and Hsu, M.: Phenolic Impregnated Carbon Ablators (PICA) for Discovery Class Missions, AIAA-96-1911, $31^{\text {st }}$ AIAA Thermophysics Conference, June 1996.

5) Kontinos, D. A. and Stackpoole, M.: Post Flight Analysis of the Stardust Sample Return Capsule Earth Entry, AIAA-2008-1197, $46^{\text {th }}$ AIAA Aerospace Sciences Meeting and Exibit, Reno, Nevada, January, 2008.

6) Okuyama, K., Kanada, T., Kato, S., Sakai, T., Suzuki, T., Fujita, K. and Nishio, S.: Thermochemical and Thermomechanical Characteristics of an Ultra Lightweight CFRP under High Temperature Environments, 2011-c-15, 28th International Symposium on Space Technology and Science ( $28^{\text {th }}$ ISTS), 5-12 June, Okinawa Prefecture, Japan.

7) Kato, S., Okuyama, K., Nisio, S., Sakata, R., Hama, K. and Inatani, Y.: Numerical Analysis of Charring Ablation for Ablative Materials of Re-Entry Capsules, Journal of the Japan Society for Aeronautical and Space Sciences, 50, No.582 (2002), pp. 255-263.(in Japanese)

8) Moyer, C. B. and Rinadal, R. A.: An Analysis of Coupled Chemically Reacting Boundary Layer and Charring Ablator, Part II , Finite Difference Solution for the In-Depth Response of Charring Materials Considering Surface Chemical and Energy Balances, NASA CR-1061, 1967.

9) Chen, Y.-K. and Milos, F. S.: Ablation and Thermal Response Program for Spacecraft Heatshield Analysis, Journal of Spacecraft and Rockets, 36, No. 3 (1999), pp. 475-483.

10) Kihara, H., Hatano, M., Nakiyama, N., Abe, K. and Nishida, M.: Preliminary Studies of Spallation Particles Ejected from an Ablator, Trans. Japan Soc. Aero. Space Sci., 49, No. 164 (2006), pp. 65-70.

11) Yoshinaka, T., Mizuno, M. and Morino, Y.: Detection of Ablator Spallation Phenomena at Arc Wind Tunnel Test, IEPC-99-025, 26th International Electric Propulsion Conference, Kitakushu, Japan, Oct.17-21, 1999.

12) Sakai, T., Okuyama, K., Kobayashi, Y., Tomita, M., Suzuki, T., Fujita, K., Kato, S. and Nishio, S.: Post-Test Sample Analysis of a Low Density Ablator Using Arcjet, 2011-e-40, 28th International Symposium on Space Technology and Science ( $28^{\text {th }}$ ISTS), 5-12 June, Okinawa Prefecture, Japan.

13) Bartlett, E. P., Abbett, M. J., Nicolet, W. E. and Moyer, C. B.: Improved Heat-Shield Design Procedures for Manned Entry Systems, Part II, Application to Apollo, Aerotherm Final Report No. 70-15, 1970.

14) Potts, R, L: Application of Integral Methods to Ablation Charring Erosion, A Review, Journal of Spacecraft and Rockets, 32, No.2, March-April (1995), pp. 200-209.

15) Quan, V.: Quasi-Steady Solution for Ablation-Erosion Heat Transfer, Journal of Spacecraft and Rockets, 7, No. 3 (1970), pp. 355-357.

16) Baer, D. and Ambrosio, A.:Heat Conduction in a Semi-Infinite Slab with Sublimation at the Surface,Planetary and Space Science, 4, June 1961, pp. 436-446.

17) Engelke, W. T., Pyron, C. M. and Pears, C. D.: Thermal and Mechanical Properties of a Nondegraded and Thermally Degrated Phenolic-Carbon Composite, NASA CR-896, 1967.

18) Schneider, P. J., Dolton, T. A. and Reed, G. W.: Mechanical Erosion of Charring Ablators in Ground-Test and Re-Entry Environments, AIAA Journal, 6, No. 1 (1967), pp. 64-72.

19) Wenger, R. S. and Laganelli, A.L.: Nuclear Radiation Effects on the Ablation Performance of Advanced Composite Heatshield Materials, AIAAA-81-1059, AIAA 16th Thermophysics Conference, California, June 23-25, 1981.

20) Bueche, J. F.: Effects of Improvements and Uncertainty in Thermophysical Properties on carbon phenolic Heatshield Thermal Performance predictions, AIAA-77-0787, AIAA 12th Thermophysics conference, New Mexico, June 27-29, 1977.

21) Potts, R, L.: Hybrid Integral/Quasi-Steady Solution of Charring Ablation, AIAA-90-1677, AIAA/ASME 5th Joint Thermophysics and Heat Transfer Conference, June 1990.

22) Peterson, D. L. and Nicolet, W. E.: Heat Shielding for Venus Entry Probes, J. Spacecraft, 11, No. 6 (1974), pp. 382-387.

23) Suzuki, T., Fujita, K., Sakai, T., Okuyama K., Kato, S. and Nishio, S.: Thermal Response Analysis of Low Density CFRP Ablator, 2011-e-41, 28th International Symposium on Space Technology and Science (28 ${ }^{\text {th }}$ ISTS), 5-12 June, Okinawa Prefecture, Japan. 